\title{
Erratum to: Stress In An Oncologist's Life: Present But Not Insurmountable
}

\section{(Students Should Not Be Discouraged Choosing Oncology as Their Future Specialisation)}

Jonatan Nowakowski $^{1}$ - Grazyna Borowiec ${ }^{1}$ - Izabela Zwierz ${ }^{1}$ - Wojciech Jagodzinski ${ }^{2}$. Radoslaw Tarkowski ${ }^{3}$

Published online: 31 October 2015

(C) American Association for Cancer Education 2015

Erratum to: J Canc Educ (2015)

DOI 10.1007/s13187-015-0928-7

The published article unfortunately contained a mistake. The presentation of Fig. 2 was incorrect. However, this error has been corrected in the referenced article.

The online version of the original article can be found at http://dx.doi.org/ 10.1007/s13187-015-0928-7.

Radoslaw Tarkowski

radoslaw.tarkowski@umed.wroc.pl

1 Wrocław Medical University, Wybrzeże L. Pasteura 1, 50-367 Wroclaw, Poland

2 Analiza Badania Rozwoj, Osiedle Stefana Batorego 11 lok 74, 60-687 Poznan, Poland

3 Department of Oncology, Division of Surgical Oncology, Wrocław Medical University, pl. Hirszfelda 12, 53-413 Wrocław, Poland 